\title{
THE EFFECT OF INCENTIVES ON JOB PERFORMANCE IN AN ORGANIZATION
}

\author{
Dr. C K GOMATHY, Mr.B.SAIMADAN REDDY, Mr.B.MUNENDRA, Mr. CH.RAKESH
}

Sri Chandrasekharendra Saraswathi Viswa Mahavidyalaya , Kanchipuram

\section{ABSTRACT}

The present study was conducted on the Goods of Motivational Impulses on Workers' Performance. The main ideal of the study was to find out position of motivational impulses and to dissect the impact of those impulses on the performance of workers. The variables which were the focus of the study were position of job Satisfaction, position of performance, effectiveness, organizational productivity, workers' fidelity and professionalism. 15 different banks of Mumbai were as target population. The sample size of the study was 154 . The exploration was grounded on simple arbitrary slice where 15 banks were named from 41 banks. Equal commensurate stratified slice was used for the distribution of the repliers. Data was collected through a questionnaire. The data was anatomized with the help of SPSS. The study established the colorful ways workers'were motivated including both financial and nonmonetary recognition grounded impulses. The results of the suppositions indicated that motivational impulses had impact on workers' performance.

Keywords: Motivational Incentives, Level of job satisfaction, Organizational Productivity, Employees loyalty.

\section{I .INTRODUCTION}

Every person has his own wants and solicitations, for that purpose he/ she works to get fulfill them. It isn't enough for an hand to be satisfied materially but non material aspects are as essential as material aspects, an hand need both to be fulfilled. Material means his payment, lagniappes, allowances, job security and other installations. While on-material aspect includes leaves, excellent working terrain, good understanding among other fellow workers and top operation, all these rudiments have much to do with provocation of hand. Workers play veritably important part in the diurnal operations of any association especially where the requests are veritably competitive and have ever- changing terrain which is supported by maturity of the proponents. The fate of an association is generally determined by its workers so it sounds logical to understand how workers can be motivated. As far as the hand's provocation is concerned, hand motivational incitement programs have been plant to be the most generally espoused fashion among associations. The purpose of the program is to award productive performance, support positive geste and stir interest in hand. Performance and how it could it could be enhanced is central to the concern of diligence and associations, thus numerous organizational scientists, are veritably much interested in, different schemes and ways related to performance and its growth impulses are one of 
those ways used in workplaces to stimulate workers in order to get asked performance.. much to do with provocation of hand. Workers play veritably important part in the diurnal operations of any association especially where the requests are veritably competitive and have ever- changing terrain which is supported by maturity of the proponents. workplaces to stimulate workers in order to get asked performance.Plutocrat is considered to be the universal motivator although other fiscal andnon-financial impulses and benefits produce a veritably special relationship between association and workers. Workers preform certain tasks; fulfill pretensions in exchange of plutocrat and other impulses package.

\section{LITERATURE REVIEW}

Compelling Attestations have been plant in the literature about the significance of the relationship between compensation \& price and the hand geste and organizational performance. Pritchard et al, (1988) study indicated that group- position.feedback increased productivity an normal of 50 over birth, group thing setting increased productivity 75 over bith, and group impulses increased productivity 76 over birth. In addition, work stations similar as job satisfaction, development intentions, and morale were more after the interventions. Jenkins et al, (1990) studied whether fiscal impulses were related. to quality and volume of performance or not. Results showed that fiscal impulses weren't related to the quality of performance rather it had a correlation with volume of performance. Bonner et al (2000) findings suggested that the type of task being performed and the type of incitement scheme being employed affected the efficacity of fiscal impulses and thus Told the design of operation account and control systems.

\section{PROBLEM STATEMENT}

In the present study quantitative approach was used. The macrocosm of the study was Banks of Karachi, Pakistan. 15 banks with different organizational superintendence's were chosen through simple arbitrary slice system. There were 512 workers in the named banks. The sample size of 154 was calculated at 95 confidence position out of 512 workers. The experimenters used commensurate stratified slice fashion to allocate exploration units to each bank. In the last step the workers were named by methodical slice from the slice frame of each bank. Data was collected through administration of a questionnaire. Near- ended questions were used in the questionnaire and matrix questions were made for the purpose of functional delineations of the generalities. The scales were constructed for; position of workers' satisfaction, motivational impulses, situations of effectiveness, product, situations of association and effectiveness of an hand. Scales were used to classify the situations and scores weregiven to each order for the purpose of suppositions testing. SPSS was used for the analysis of the data. Chi-square test and pvalue were applied to dissect the suppositions of the study from which the conclusion was drawn.

From the data anatomized, it's egregious that financial incitement play a vital part in adding hand . performance. This is in line with the view of Jack Welch that "If you pick the right people and give them the occasion to spread their bodies-and put compensation and incitement as a carrier behind ityou nearly slip " $t$ have to manage them." The results of the suppositions tests formulated from the four

Objects of this study were bandied below; 
The first thesis is that payment and stipend have a motivating eventuality in adding hand performance in an association. This is harmonious with the view of Laura (2016); she asserts that the payment a worker is paid by his employer can have a great influence on his performance in the administration. An hand doesn " $\mathrm{t}$ simply view his payment as an quantum; he sees it as the value his employer places on him as an hand. The position of appreciation he feels can have a direct impact on his overallperformance.The alternate thesis indicated that borderline benefits have an effect on hand performance. This is inconsistent with the view of Mussie, Kathryn \& Abel, (2013), they asserted that workers decreasingly value hand benefits as part of their overall compensation package. This is what operation philosopher Frederick Hertzberg would call a , hygiene factor "e. The idea is that if you slip "e $\mathrm{t}$ give people enough hygiene factors they will be demotivated, but not inescapably motivated The third result of the thesis shows that lagniappes have an effect on hand performance. This is in harmonious with the view of Ruth (2016), she asserts that Lagniappes for whatever reason affect hand performance in a number of different ways similar as perfecting hand morale, provocation and productivity.

\section{SCOPE OF THE STUDY}

1. To explore the multitudinous types of motivational impulses entered by workers in banking sector of India.

2. To dissect the impact of those motivational impulses on workers' work performance; that either their performance after getting different impulses increases or not.

\section{V.RESULTS}

The research leads to the improvement of the effect of incentives on job performance. It also benefits students, researchers and scholars who are interested in developing further studies on the subject matter.

\section{VI.CONCLUSION}

Monetary incitement smirch is seen as one of the most important strategies in the mortal resource operation function as it influences the productivity and growth of an association. Hence, ultramodern . commercial associations have supposed it imperative to incorporate effective financial incitement scheme for workers as part of their commercial pretensions and objects. This is believed to shape a work force concentrated on strategic performance pretensions and able of achieving them. This exploration work is also about financial impulses and workers performance. The total incitement scheme is grounded on a redefining of hand incitement and investment systems into a handdriven system. Monetary Incitement scheme have been raising questions about the structure of being and frequently rigid pay systems for some time.

Thus, this study "e s idea of financial incitement goes beyond pay alone to propose an incitement system- a group of variables that together encompass the kinds of kinds of financial impulses that moment " $\mathrm{s}$ workers want from work. Pay is among them, of course ( including both base pay, or payment, and onetime pay entered in form of overtime or lagniappes). But in addition to financial incitement, contemporary . Workers want and are decreasingly demanding incitement diversity and incitement choice. In moment " $\mathrm{s}$ different, employers are chancing that workers want a range of different effects from the work place. Workers will indeed 
change some position of base pay to get some of the other effects they want. Conclusively, the significance of effective financial incitement scheme can not be overemphasized in a shot to attracting and motivating workers for bettered organizational productivity. A major task from a mortal resource operation and artificial relations perspective is to understand how to design and administer financial incitement programs that stylish meet the pretensions of employers and workers in the employment exchange. In this sense both the employers and the workers profit and in general Appreciatively and significantly impact the overall commercial performance. There's a relationship between hand performance and financial incitement, it's possible to fete . the actuality of a trend that suggest that incitement, when both conception have a duly designed manage. these can impact the workers to show better performance.

\section{REFERENCES}

1.Dr.C K Gomathy, Article: A Study on the recent Advancements in Online Surveying, International Journal of Emerging technologies and Innovative Research ( JETIR ) Volume 5 | Issue 11 | ISSN : 2349-5162, P.No:327-331, Nov-2018

2.Dr.C.K.Gomathy,C K Hemalatha, Article: A

Study On Employee Safety And Health

Management International Research Journal Of

Engineering And Technology (Irjet)- Volume: 08

Issue: 04 | Apr 2021
3. Dr.C K Gomathy, Article: A Study on the Effect of Digital Literacy and information Management, IAETSD Journal For Advanced Research In Applied Sciences, Volume 7 Issue 3, P.No-51-57, ISSN NO: 2279-543X,Mar/2018

4. Dr.C K Gomathy, Article: An Effective Innovation Technology In Enhancing Teaching And Learning Of Knowledge Using Ict Methods, International Journal Of Contemporary Research In Computer Science And Technology (Ijcrcst) E-Issn: 2395-5325 Volume3, Issue 4,P.No-10-13, April '2017

5.Dr.C K Gomathy, Article: Supply chain-Impact of importance and Technology in Software Release Management, International Journal of Scientific Research in Computer Science Engineering and Information Technology ( IJSRCSEIT ) Volume 3 | Issue 6 | ISSN : 2456-3307, P.No:1-4, July-2018

\section{Author's Profile:-}

\section{1.}

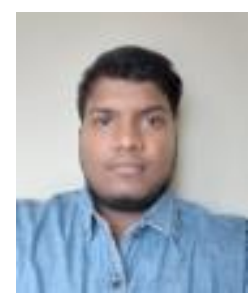

Mr.B.SAIMADANREDDY Student, B.E. Computer Science and Engineering, Sri Chandrasekharendra SaraswathiViswa Mahavidyalaya deemed to be university, Enathur, Kanchipuram, India. His Area of interest in Human Resources Development 
2.

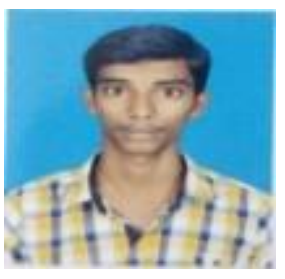

Mr.B.MUNENDRA,Student, B.E. Computer Science and Engineering, Sri Chandrasekharendra SaraswathiViswa Mahavidyalaya deemed to be university, Enathur, Kanchipuram, India. His Area of interest in Human Resources Development

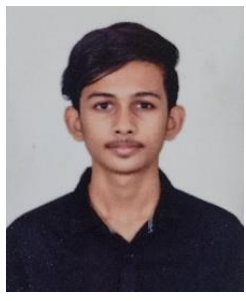

3.

Mr.CH.RAKESH Student, B.E. Computer Science and Engineering, Sri Chandrasekharendra
SaraswathiViswa Mahavidyalaya deemed to be university, Enathur, Kanchipuram, India. His Area of interest in Human Resources Development

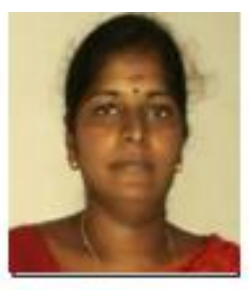

4.

Dr.C.K. GOMATHY is Assistant Professor in Computer Science and Engineering at Sri Chandrasekharendra SaraswathiViswa Mahavidyalaya deemed to be university, Enathur, Kanchipuram, India. Her area of interest is Software Engineering, Web Services, Knowledge Management and IOT. 